\title{
ANALYSIS OF OUTBREAK RESPONSE IMMUNIZATION PROGRAM FOR PREVENTION OF DIPHTERIA DISEASE AND HEALTH WORKLOAD
}

\author{
Atnesia Ajeng, Ika Oktaviani, Eka Mardiana A \\ Universitas Muhamadiyah Tangerang, Banten
}

\begin{abstract}
Bcakground: Outbreak Response Immunization (ORI) is one way of overcoming the extraordinary event of a disease by giving immunization. ORI is a strategy to achieve individual and community immunity of up to 90 to $95 \%$ so that diphteria outbreaks can be overcome. This study aimed to investigate the outbreak response immunization program for prevention of diphteria disease and its health workload.

Subjects and Method: This was a cohort study conducted at Tanggerang, Banten from May to July 2019. A sample of 100 health workers was selected for this study by purposive sampling. The dependent variable was outbreak response immunization program. The independent variables were prevention of diphteria disease and health workload. The data were collected by a set of questionnaire. The data were analyzed using structural equation modeling (SEM).

Results: ORI program increased workload of the health workers but it was statistically not significant $(b=0.75 ; p=0.152)$. ORI program increased the incidence of diphteria but it was statistically not significant $(b=0.14 ; p=0.331)$. ORI program was affected by workload and diphteria. Workload was affected by diphteria.

Conclusion: ORI program is affected by workload of the health workers and there is no statistically significant association between ORI program and diphteria.
\end{abstract}

Keywords: outbreak response immunization, diphteria, workload, health worker

Correspondence:

Atnesia Ajeng. Universitas Muhammadiyah Tangerang, Banten. Email: atnesia.ajeng@gmail.com. Mobile: 085735406393. 